\title{
Relationship between Primary Nodal Generalized Osteoarthritis with Tissue Antigens HLA-A and HLA-B in the Western Black Sea Region of Turkey
}

\author{
Cemal Taslıgil ${ }^{1}$, Sirzat Cogalgil ${ }^{1}$, Esra Tug ${ }^{2}$, Burak Tonuk ${ }^{1}$, \\ Ozlem Sahin ${ }^{1}$ and Dilek Dogruer ${ }^{2}$
}

\begin{abstract}
Objective To investigate the relationship between patients diagnosed with nodal generalized osteoarthritis (NGOA) and tissue antigens HLA-A and HLA-B in the Western Black Sea Region of Turkey.

Patients and Methods Forty-six patients with NGOA (64.74 \pm 8.46$)$ and 60 controls $(62.32 \pm 6.8)$ were included in the study. Inclusion criteria were: (i) stage 2 and higher OA of the hand and knee based on the Kellgren-Lawrence classification, and (ii) stage 2 and higher lumbar disc degeneration according to Lawrence classification. Family histories were taken from patients. HLA-A and HLA-B were typed by PCR using sequence specific primer.

Results The frequencies of HLA-A*02 and HLA-B ${ }^{*} 38$ were $58.7 \%$ and $15.2 \%$, respectively, in patients with NGOA, and there was a statistically significant relationship between the disease and HLA-A*02 and HLA-B* 38. The relationship between positive family history and HLA-B 44 allele was also statistically significant. In the control group, the frequency of HLA-A 29 was $11.7 \%$ and it was statistically significant.

Conclusion To our knowledge this is the first study to demonstrate the epidemiologic association between HLA-A* 02 and HLA-B 38 with NGOA in our population. We conclude that, HLA-B* 44 positivity may be associated with familial NGOA and HLA-A"29 may be a preventive factor against NGOA.
\end{abstract}

Key words: primary nodal generalized osteoarthritis, HLA-A allelles, HLA-B allelles, tissue antigens

(Intern Med 50: 545-550, 2011)

(DOI: 10.2169/internalmedicine.50.4646)

\section{Introduction}

Osteoarthritis (OA) is the most common age-related joint disorder, which develops as a result of the imbalance between the destruction and reconstruction of joint cartilage and subchondral bone (1). It was described by Kellgren and Moore in 1952 (2). It is called generalized OA if 3 or more joints are affected. Nodal generalized OA (NGOA) is a subset characterized by polyarticular interphalangeal and thumb base OA, female preponderance, early inflammatory component, and Heberden node formation; of all OA subsets, familial tendency is particularly recognized (1). OA is a dynamic process comprised of destruction and reconstruction, triggered by different biochemical and mechanic factors. Commonly it starts with no apparent reason and is referred to as idiopathic or primary OA. It may be hereditary or develop secondarily after joint trauma, infection, metabolic or neurological disease. The molecular pathogenesis is not fully understood, although genetic, environmental, metabolic and biomechanical factors seem to contribute to the pathogenesis (3).

The Human Leukocyte Antigen (HLA) system is very informative for population genetics because it is widely polymorphic and includes tightly linked loci, whose antigens are a key link in the immune response. Population analysis in various regions of the world provides grounds for investigation of the linkage between HLA antigens and various disor-

${ }^{1}$ Department of Physican Medicine and Rehabilitation, Abant Izzet Baysal University, Izzet Baysal Medical School, Turkey and ${ }^{2}$ Department of Medical Genetics, Abant Izzet Baysal University, Izzet Baysal Medical School, Turkey Received for publication October 7, 2010; Accepted for publication November 28, 2010 Correspondence to Dr. Esra Tug, esratug@ hotmail.com 
ders (4). The pof excessive immune complexes in the synovium and cartilage of patients with NGOA suggests an autoimmune etiology (5). Even though the association between the NGOA and some genes is known, the relationship between HLA and NGOA is yet to be clarified. Genetic factors have been extensively studied in rheumatic diseases and they may be associated with either development or severity (6). Despite marked familial predisposition, genetic markers in NGOA have been investigated in a few studies. Only four studies have presented data on the frequencies of HLA antigens $(7,8)$. One of these studies reported an increased frequency of HLA-A* $01 \mathrm{~B}^{*} 08$ (7) and another reported an increased frequency of HLA-B ${ }^{*} 08$ while two studies found no relation (8). The distribution of HLA antigens in several ethnic groups in the world has been reported $(9,10)$. A few reports are available in the Turkish population (11), but to our knowledge, there is no study that shows the relationship between NGOA and HLA in the Turkish population. In this study, we aimed to investigate the relationship between the patients diagnosed with NGOA and tissue antigens HLA-A and HLA-B in the Western Black Sea region of Turkey.

\section{Materials and Methods}

\section{Patients}

Forty-six patients with NGOA, aged between 42 and 79 years (mean age $64.74 \pm 8.46$ years), who presented with hand or knee OA were enrolled in this study. They were all diagnosed based on the American College of Rheumatology criteria for the classification of hand or knee OA (12). Radiographic staging was made for lumbar OA. Sixty healthy volunteers in the age range of 50 and 77 years (mean age $62.32 \pm 6.8$ years) without clinical or radiological signs of hand or knee OA served as controls. People from the same region were chosen for the control group because of ethnic and geographic relevancy. Human Clinical and Laboratory Research Local Ethics Committee approved the study. All patients were informed about the study, and their consent was taken for the diagnostic and molecular testing of HLA.

Hand and knee radiographs were all reviewed according to Kellgren-Lawrence scoring system for knee and hand and Lawrence classification for lumbar region (13), by two consultant radiologists who had no information about the patients' clinical situation.

\section{Design}

\section{Radiological assessment}

Each subject had postero-anterior plain radiographs of both hands at the time of evaluation. Radiographs of both knees were taken antero-posteriorly while the subjects were standing, feet were $10^{\circ}$ externally rotated, knees and thighs were in contact with the vertical platform anteriorly and $\mathrm{x}$ ray device was angled $10^{\circ}$ vertically and caudally. Hand and kneesradiographs were all reviewed by two consultant radiologists. Radiographs were graded according to the criteria described by Kellgren and Lawrence (13) in the Atlas of Standard Radiographs. OA was graded as follows: $0=$ no OA, grade $1=$ doubtful $\mathrm{OA}$, grade $2=$ minimal $\mathrm{OA}$, grade $3=$ moderate OA, and grade 4=severe OA. Definite hand and knee OA was diagnosed when the score was $\geq 2$.

Lumbar vertebrate (L1-L5) radiographies were taken in the lateral decubitus position and scored according to Lawrence classification (13). Definite lumbar OA was diagnosed in the presence of a grade $\geq 2$.

Patients who had OA in three or more areas were diagnosed with generalized OA (14).

\section{Inclusion criteria}

1. Presence of hand, knee and lumbar OA according to American Rheumatism Association,

2. Radiographically stage 2 or higher OA according to Kellgren and Lawrence Scale,

3. Age $\geq 40$, being postmenopausal for females,

4. No pathological findings in blood samples in both patient and control groups.

\section{Exclusion criteria}

1. Presence of an inflammatory disease such as rheumatoid arthritis, psoriatic arthritis,

2. Presence of erosive OA and chondrocalcinosis,

3. Patients who had previous orthopedic surgery or fracture,

4. Patients who had secondary OA (post-traumatic, metabolic, and inflammatory rheumatic disease),

6. Age $<40$,

7. Smoking or alcohol consumption.

Sex, age, weight, and height of all subjects were recorded. Pedigrees were drawn for all patients and finger nodules were asked for patients' parents, children and siblings. Complete blood count, biochemical tests, erythrocyte sedimentation rate, CRP and rheumatoid factor (RF) were ordered for all subjects. Body mass index (BMI) was calculated and subjects were divided into six groups as normal (< $\left.25 \mathrm{~kg} / \mathrm{m}^{2}\right)$, borderline obesity $\left(25-27 \mathrm{~kg} / \mathrm{m}^{2}\right)$, mild obesity $\left(27-30 \mathrm{~kg} / \mathrm{m}^{2}\right)$, moderate obesity $\left(30-35 \mathrm{~kg} / \mathrm{m}^{2}\right)$, critical obesity $\left(35-40 \mathrm{~kg} / \mathrm{m}^{2}\right)$ and severe obesity $\left(>40 \mathrm{~kg} / \mathrm{m}^{2}\right)(15)$.

\section{HLA typing}

Three $\mathrm{mL}$ of venous blood samples were collected in EDTA coated tubes from each of the 106 subjects and genomic DNAs were extracted by "QIAamp DNA Blood Mini Kit" (Qiagen, Germany). Typing of HLA class I (HLA-A and -B) was performed using HLA-A Low Resolution (Res.) Sequence Specific Primer (SSP) and HLA-B Low Res. SSP (Olerup SSP AB, Sweden) with a thermocycler (Takara, Japan) according to the guidelines of the manufacturer. 
Table 1. Statistical Comparison of Two Groups for Age, Gender and BMI

\begin{tabular}{lccc}
\hline & $\begin{array}{c}\text { Patients* } \\
(\mathbf{n}=\mathbf{4 6})\end{array}$ & $\begin{array}{c}\text { Controls } \\
(\mathbf{n}=\mathbf{6 0})\end{array}$ & p values \\
\hline Age (years) & $64.74 \pm 8.46$ & $62.32 \pm 6.8$ & 0.105 \\
BMI** & $28.86 \pm 4.7$ & $30.82 \pm 4.38$ & $0.03 * * *$ \\
Male & $8.69 \%$ & $8.3 \%$ & 0.607 \\
Female & $(\mathrm{n}=4)$ & $(\mathrm{n}=5)$ & 0.6 \\
\hline
\end{tabular}

* Patients with nodal generalized osteoarthritis

** Body Mass Index (weight $(\mathrm{kg}) /$ height $\left.(\mathrm{m})^{2}\right)$

$* * *$ Statistically significant

Table 2. Radiographic Staging of Nodal Hand OA Patients and the Relationships between BMI and Stage

\begin{tabular}{lccccc}
\hline & Stage 2 & Stage 3 & Stage 4 & Total & p value \\
\hline Patients* & $\begin{array}{l}26.1 \% \\
(\mathrm{n}=12)\end{array}$ & $\begin{array}{c}19.6 \% \\
(\mathrm{n}=9)\end{array}$ & $\begin{array}{c}54.3 \% \\
(\mathrm{n}=25)\end{array}$ & $\begin{array}{c}100 \% \\
(\mathrm{n}=46)\end{array}$ & \\
BMI** & $29.68 \pm 4.31$ & $29.4 \pm 6.21$ & $28.27 \pm 4.44$ & $28.86 \pm 4.73$ & 0.369 \\
\hline
\end{tabular}

* Patients with nodal hand osteoarthritis

** Body Mass Index (weight $(\mathrm{kg}) /$ height $\left.(\mathrm{m})^{2}\right)$

\section{Statistical analysis}

"SPSS (Statistical Package for Social Sciences) for Windows 17.0" was used for statistical analysis of the data. Continuous variables were expressed as mean \pm standard deviation. Continuous variables were compared with t-test, categorical variables were compared with chi square test. Post hoc Tukey test and ANOVA were used for comparing parametric variables between groups. Kruskal-Wallis and chi square tests were used for comparing nonparametric variables and percentages. Statistical significance was accepted as $\mathrm{p}<0.05$ for all tests.

\section{Results}

Demographic characteristics of both groups are presented in Table 1. There was no significant difference in age and gender $(p>0.05)$ between the two groups but there was a significant difference between the two groups for BMI $(\mathrm{p}<$ 0.05) (Table 1).

Radiographic staging of nodal hand OA patients and the relationships between BMI and stage are presented in Table 2. There was a no significant relation between nodal hand OA and BMI ( $\mathrm{p}>0.05)$.

The most commonly determined HLA-A alleles were HLA-A 02 , HLA-A 24 and HLA-A 11 , with frequencies of $58.7 \%, 30.4 \%$ and $23.9 \%$, respectively, whereas in the patient group, the most common HLA-B alleles were HLA-B* 35 , HLA-B ${ }^{*} 15$ and HLA-B 38 , with frequencies of $39.1 \%$, $17.4 \%$ and $15.2 \%$, respectively. Comparison of the groups revealed significant differences in HLA-A*02 and HLA-B ${ }^{*} 38$ $(\mathrm{p}<0.05)$. While HLA-A 29 was found in $11.7 \%$ of the patient group, it was not identified in the control group $(\mathrm{p}<$
$0.05)$.

There was no statistically significant relation between the two groups in other HLA-A (HLA-A 03, "11, "23, ${ }^{*} 24,{ }^{*} 25$, "26, "30, "31, "32, "33, "68, "69 and "74) and HLA-B alleles (HLA-B $07,{ }^{*} 08,{ }^{*} 13,{ }^{*} 15,{ }^{*} 18,{ }^{*} 27,{ }^{*} 35,{ }^{*} 39,{ }^{*} 40,{ }^{*} 41,{ }^{*} 44$, "45, "48, "49, ${ }^{*} 50,{ }^{*} 51$ and $\left.{ }^{*} 52\right)(\mathrm{p}>0.05)$. In the control group, one individual's HLA-B allele could not be determined.

When we compared the disease severity with HLA-A and $B$ alleles, we found no significant relationship between HLA-A alleles and stages while HLA-B ${ }^{*} 51$ allele was significantly related to stage 3 of the disease $(\mathrm{p}<0.05)$.

Six subjects in the patients group with HLA-B ${ }^{*} 44$ allele had a positive family history and there was a statistically significant relationship between HLA-B 44 and positive family history $(\mathrm{p}<0.05)$. There was no relation between other HLA alleles and family history ( $p>0.05)$. HLA-A and HLA-B alleles determined in both groups are shown in Table 3 .

\section{Discussion}

NGOA is diagnosed in the presence of OA in three or more joints and Heberden and Bouchard nodules, which occur as a result of interphalangeal joint involvement. Genetics is known to be a component of the etiology/pathogenesis of NGOA. Familial predisposition lends support to a genetic component (20). It has been argued that OA is not the result of a single genetic anomaly but rather it is under the influence of multiple genes and environmental factors. Genetic analyses have shown that ADAM12, BMP2, CD36, COX2, NCOR2 genes are related to OA and associations of loci on the $2 \mathrm{nd}$, 4th, 6th, 7th, 11th, 16th chromosomes and $\mathrm{X}$ chro- 
Table 3. Association of HLA-A and HLA-B with Nodal Generalized OA in the Study Population

\begin{tabular}{|c|c|c|c|c|c|c|c|c|c|}
\hline $\begin{array}{l}\text { HLA-A } \\
\text { alleles }\end{array}$ & $\begin{array}{c}\text { Patient } \\
n=46\end{array}$ & $\begin{array}{c}\text { Controls } \\
\mathbf{n}=60\end{array}$ & p value & $\begin{array}{c}\text { Gene } \\
\text { frequency** }\end{array}$ & $\begin{array}{c}\text { HLA-B } \\
\text { alleles }\end{array}$ & $\begin{array}{c}\text { Patient } \\
n=46\end{array}$ & $\begin{array}{c}\text { Controls } \\
\mathbf{n}=59\end{array}$ & $p$ value & $\begin{array}{c}\text { Gene } \\
\text { frequency** }\end{array}$ \\
\hline$A * 01$ & $\begin{array}{c}19.6 \% \\
n=9\end{array}$ & $\begin{array}{c}11.7 \% \\
n=7\end{array}$ & 0.197 & 11.00 & B*07 & $\begin{array}{c}4.3 \% \\
n=2\end{array}$ & $\begin{array}{c}8.5 \% \\
n=5\end{array}$ & 0.334 & 8.3 \\
\hline$A * 02$ & $\begin{array}{c}58.7 \% \\
\mathrm{n}=27\end{array}$ & $\begin{array}{l}40 \% \\
n=24\end{array}$ & $0.043 \dagger$ & 21.00 & $B * 08$ & $\begin{array}{c}4.3 \% \\
n=2\end{array}$ & $\begin{array}{c}8.5 \% \\
n=5\end{array}$ & 0.334 & 5.6 \\
\hline$A * 03$ & $\begin{array}{c}17.4 \% \\
n=8\end{array}$ & $\begin{array}{l}30 \% \\
n=18\end{array}$ & 0.102 & 8.00 & $B * 13$ & $\begin{array}{c}4.3 \% \\
n=2\end{array}$ & $\begin{array}{c}5.1 \% \\
n=3\end{array}$ & 0.617 & 4.20 \\
\hline$A^{*} 11$ & $\begin{array}{c}23.9 \% \\
n=11\end{array}$ & $\begin{array}{c}13.3 \% \\
n=8\end{array}$ & 0.125 & 5.60 & $B * 15$ & $\begin{array}{c}17.4 \% \\
n=8\end{array}$ & $\begin{array}{c}11.9 \% \\
\mathrm{n}=7\end{array}$ & 0.299 & 0.60 \\
\hline$A * 23$ & $\begin{array}{c}4.3 \% \\
n=2\end{array}$ & $\begin{array}{l}10 \% \\
n=6\end{array}$ & 0.239 & 5.60 & $B * 18$ & $\begin{array}{c}8.7 \% \\
n=4\end{array}$ & $\begin{array}{c}11.9 \% \\
n=7\end{array}$ & 0.423 & 11.1 \\
\hline$A * 24$ & $\begin{array}{c}30.4 \% \\
n=14\end{array}$ & $\begin{array}{l}35 \% \\
n=21\end{array}$ & 0.388 & 31.9 & $B * 27$ & $\begin{array}{c}4.3 \% \\
n=2\end{array}$ & $\begin{array}{c}- \\
\mathrm{n}=0\end{array}$ & 0.190 & 3.50 \\
\hline$A * 25$ & $\begin{array}{c}4.3 \% \\
n=2\end{array}$ & $\begin{array}{c}3.3 \% \\
n=2\end{array}$ & 0.585 & 1.3 & $B * 35$ & $\begin{array}{c}39.1 \% \\
n=18\end{array}$ & $\begin{array}{l}39 \% \\
n=23\end{array}$ & 0.573 & 41.7 \\
\hline$A * 26$ & $\begin{array}{c}8.7 \% \\
n=4\end{array}$ & $\begin{array}{c}13.3 \% \\
n=8\end{array}$ & 0.335 & 6.9 & $B * 38$ & $\begin{array}{c}15.2 \% \\
\mathrm{n}=7\end{array}$ & $\begin{array}{c}3.4 \% \\
n=2\end{array}$ & $0.036 \dagger$ & 6.9 \\
\hline$A * 29$ & $\begin{array}{c}- \\
n=0\end{array}$ & $\begin{array}{c}11.7 \% \\
n=7\end{array}$ & $0.016 \dagger$ & 1.4 & $B * 39$ & $\begin{array}{c}10.9 \% \\
\mathrm{n}=5\end{array}$ & $\begin{array}{c}3.4 \% \\
n=2\end{array}$ & 0.130 & 6.9 \\
\hline$A * 30$ & $\begin{array}{c}4.3 \% \\
n=2\end{array}$ & $\begin{array}{c}3.3 \% \\
n=2\end{array}$ & 0.585 & 11.1 & $B * 40$ & $\begin{array}{c}8.7 \% \\
n=4\end{array}$ & $\begin{array}{c}15.3 \% \\
n=9\end{array}$ & 0.240 & 4.7 \\
\hline$A * 31$ & $\begin{array}{c}- \\
n=0\end{array}$ & $\begin{array}{c}1.7 \% \\
n=1\end{array}$ & 0.566 & 2.8 & $B * 41$ & $\begin{array}{c}4.3 \% \\
n=2\end{array}$ & $\begin{array}{c}8.5 \% \\
n=5\end{array}$ & 0.334 & 4.2 \\
\hline$A * 32$ & $\begin{array}{c}8.7 \% \\
n=4\end{array}$ & $\begin{array}{c}1.7 \% \\
n=1\end{array}$ & 0.110 & 0.53 & $B * 44$ & $\begin{array}{c}13.0 \% \\
\mathrm{n}=6\end{array}$ & $\begin{array}{c}3.4 \% \\
n=2\end{array}$ & 0.07 & 6.9 \\
\hline$A * 33$ & $\begin{array}{c}- \\
n=0\end{array}$ & $\begin{array}{c}3.3 \% \\
n=2\end{array}$ & 0.318 & 4.2 & $B * 45$ & $\begin{array}{c}2.2 \% \\
\mathrm{n}=1\end{array}$ & $\begin{array}{c}- \\
n=0\end{array}$ & 0.269 & 0.4 \\
\hline$A * 68$ & $\begin{array}{c}4.3 \% \\
n=2\end{array}$ & $\begin{array}{l}10 \% \\
n=6\end{array}$ & 0.239 & 8.3 & $B * 48$ & $\begin{array}{c}4.3 \% \\
n=2\end{array}$ & $\begin{array}{c}- \\
n=0\end{array}$ & 0.190 & 0.42 \\
\hline$A * 69$ & $\begin{array}{c}- \\
n=0\end{array}$ & $\begin{array}{c}1.7 \% \\
n=1\end{array}$ & 0.566 & - & $B * 49$ & $\begin{array}{c}2.2 \% \\
\mathrm{n}=1\end{array}$ & $\begin{array}{c}6.8 \% \\
n=4\end{array}$ & 0.275 & 4.2 \\
\hline \multirow[t]{3}{*}{$A^{* 74}$} & $\begin{array}{c}4.3 \% \\
n=2\end{array}$ & $\begin{array}{c}- \\
n=0\end{array}$ & 0.186 & 0.85 & $B * 50$ & $\begin{array}{c}10.9 \% \\
n=5\end{array}$ & $\begin{array}{c}5.1 \% \\
n=3\end{array}$ & 0.230 & 6.9 \\
\hline & & & & & $B * 51$ & $\begin{array}{c}0.08 \% \\
n=4\end{array}$ & $\begin{array}{c}0.18 \% \\
n=11\end{array}$ & 0.121 & - \\
\hline & & & & & $B * 52$ & $\begin{array}{c}0.4 \% \\
n=2\end{array}$ & $\begin{array}{c}0.05 \% \\
n=3\end{array}$ & 0.617 & - \\
\hline
\end{tabular}

$\dagger$ statistically significant $\mathrm{p}$ value, ${ }^{* *}$ Gene frequency of related allele in Turkish population $(16,17,18,19)$.

mosome with OA have been demonstrated (21). Relationships between different HLA alleles and OA or OA variants are also known. Indeed, the findings of Saito and colleagues (22) who examined the synovial tissue of the medial and lateral compartments of the patients with knee OA histochemically and showed more antibodies against type II collagen, and CD68, CD4 and HLA-DR positivity on the medial surface, corroborates the relationship between HLA and this disease.

Wakitani et al (23) showed that the frequencies of HLAB*62 and HLA-Cw4 in Japanese patients with NGOA were higher. Pattrick et al (24) found an increase in the frequencies of HLA-A*01 and HLA-B*08 in NGOA patients and they reported a possible relation between A1B8 haplotype and NGOA. Linkage analysis in a healthy Turkish population showed that the most frequent HLA haplotypes in that population were $\mathrm{B} 35 \mathrm{Cw} 4, \mathrm{~A} 1 \mathrm{~B} 8$ and $\mathrm{B} 27 \mathrm{Cw} 2$, with $\mathrm{A} 1 \mathrm{~B} 8$ haplotype being more frequent in the western Turkey region (16).

With frequencies of $58.7 \%$ and $39 \%$, HLA-A 02 and HLA-B 35 , respectively, were the most common alleles in NGOA patients in our study. Compared to the control group, HLA-A*02 was statistically significant. However, such a significant relation was not observed in HLA-B*35 allele between two groups. HLA-B*38 was the third most frequent allele $(15.2 \%)$ and there was a significant difference between the control and patient groups (Table 3). Despite the fact that previous studies conducted on a Turkish population showed that, with a frequency of $38.2 \%$, HLAA*02 was the most common HLA-A allele, its frequency among NGOA patients in our region $(58.7 \%)$ was above the mean frequency in Turkey. The most common HLA-B allele in our region was HLA-B*35 (39\%), though this allele is the second most common allele in the Turkish population (24.7\%) (16). Arnaiz-Villena et al (18) reported the frequency of HLA-B 38 allele in the Turkish population as $3.3 \%$. The frequencies of the same HLA alleles among NGOA patients in our region were higher than the means of Turkey. Tokgoz et al (16) revealed that, in terms of the HLA data, except for minor differences, the populations in geographic regions of Turkey were homogenous. However, lower frequencies of these alleles found by Tokgoz and colleagues may be atributed to the fact that they covered all the Black Sea region. In fact, it would be more appropriate to 
assess Eastern and Western Black Sea regions separately. Our results suggest that the distribution of the HLA alleles reported in the Turkish population is not homogenous.

In contrast to the results of Pattrick et al (24), we did not find any relation between HLA-A*01 and HLA-B* 08 alleles in the patient group and NGOA. On the other hand, our results were similar to those of Clague et al (25) who showed a relationship between HLA-A*02 and NGOA in a British population. Our literature review did not produce any study reporting a relation between NGOA and HLA-B ${ }^{*} 38$. This suggests that the relationship may be specific to patients with NGOA in our region. Moreover, this result supports that HLA class I antigens can show a different clinic correlation in different ethnic groups.

Although there are a couple of differences in antigen frequencies among geographic regions, $\mathrm{A}^{*} 02, \mathrm{~A}^{*} 09$ and $\mathrm{A}^{*} 01$ are the most common A-locus antigens (11). When the Turkish population is compared to European Caucasoids, few differences in antigen frequencies can be seen. In the Turkish population, the frequencies of HLA-A *01, *02 and *09 are higher. The frequencies of HLA-A are similar in Turkish, European Caucasoid and Greek populations. In Japanese Orientals, the frequency of HLA-A*01 is lower than other populations (16). In the present study, in addition to being the most frequent HLA allele, the frequency of HLA-A 02 was above the mean of Turkey and so was *01 allele (19.6\%). *09 allele, on the other hand, was not determined in our study group.

Ersoy (11) revealed that the most common B locus antigens in Turks were $B^{*} 05, B^{*} 35$ and $B^{*} 12$. In the present study, we did not detect HLA-B ${ }^{*} 05$ or $\mathrm{B}^{*} 12$ while $\mathrm{B}^{*} 35$ was the most common HLA-B allele (39.1\%).

Relationships between hand OA and B35DQ1, B40DQ1 and DR2DQ1 haplotypes and roles of A24B18 or A25B18 and B18DR5 haplotypes as protective factors against nodal hand OA have been reported (26). While HLA-A*29 allele was absent among the subjects of our patient group, it was found in $11.7 \%$ of the subjects in the control group and the difference was statistically significant. In the light of these results, we conclude that HLA-A*29 allele, which was not found to be significant in previous studies, has a protective role against NGOA in our region. Furthermore, there was a statistically significant relation between disease severity and HLA-B*51 allele. Individuals with HLA-B*51 allele had stage 3 NGOA. Therefore, one can conclude that HLA-B ${ }^{*} 51$ allele accompanies osteoarthritis with a more severe course.

Previous studies reported that HLA-A*02 allele was the most frequent HLA-A subgroup among all populations whereas HLA-A 24 allele is present only in Caucasians but not in African-Americans or Asians (27). In our control group, the frequencies of HLA-A*02, HLA-A*03 and HLA$\mathrm{B}^{*} 40$ alleles were $40 \%, 30 \%$, and $15.3 \%$, respectively, and these are significantly higher than those reported by other studies from this country $(16,17)$.

In NGOA patients, familial predisposition in the presence degenerative nodules of the hand joints has long been known (15). A familial tendency in concomitant hand and knee OA has also been reported (6). In a study on dizygotic and monozygotic female twins with hand and knee OA, Spector et al (28) investigated the effects of genetic and environmental factors and reported that the influence of genetic factors, independent of environmental and demographic factors, varied between 39-95\%. In the present study, all patients with HLA-B ${ }^{*} 44$ allele had a positive family history. Hence, it is possible to conclude that a strong familial predisposition exists in NGOA patients with HLA$\mathrm{B}^{*} 44$ allele.

In the present study, we found that HLA-A*02 and HLAB 38 alleles can be related to NGOA, an association that has not been reported elsewhere. We found some evidence that suggests HLA-A*29 allele having a protective role in NGOA development and HLA-B 51 allele is related to the severity of the disease. Further, we found that there is a strong familial predisposition among patients with NGOA and HLAB*44 allele.

Similar studies must be carried out in larger groups and in different geographical regions to determine the exact relation between NGOA and HLA haplotypes since this is an autoimmune disease and shows a multifactorial inheritance.

\section{The authors state that they have no Conflict of Interest (COI).}

\section{Acknowledgement}

We thank the patients for participation in this research. In addition, this work was funded by the Abant Izzet Baysal University Scientific Research Projects and Coordination Unit (Project number: 2009.08.03.303).

\section{References}

1. Cooke TD. Pathogenetic mechanisms in polyarticular osteoarthritis. Clin Rheum Dis 11: 203-238, 1985.

2. Kellgren JH, Moore R. Generalized osteoarthritis and Heberden's nodes. Brit Med J 1: 181-187, 1952.

3. Hurley MV, Scott DL, Rees J, Nweham DJ. Sensorimotor changes and functional performance in patients with knee osteoarthritis. Ann Rheum Dis 56: 641-648, 1997.

4. Nersisyan VM, Martirosyan IG, Musaelyan NO, Meliksetian NO. Distribution of HLA antigens in the Armenian population of $\mathrm{Na}-$ gornyi Karabakh. Russ J Genet 38: 843-846, 2002.

5. Solomon L. Clinical Features of Osteoarthritis. In: Kelley's Textbook of Rheumatology. 6th ed. Kelley WN, Harris ED, Ruddy S, Eds. W Saunders Company, Philadelphia, 2001: 1409-1418.

6. Felson DT, Couropmitree NN, Chaisson CE, et al. Evidence for a Mendelian gene in a segregation analysis of generalized radiographic osteoarthritis: the Framingham Study. Arth Rheum 41: 1064-1071, 1998.

7. Lawrence JS, Gelsthorpe K, Morell G. Heberden's nodes and HLA markers in generalised osteoarthritis. J Rheumatol 10: 32-33, 1983.

8. Brodsky A, Appelboam T, Govaerts A, Famaey JP. HLA antigens and Heberden nodes. Acta Rheumatol 3: 95-100, 1979.

9. Baur MP, Danilous JA. Population Analysis of HLA-B, C, DR and Other Genetic Markers. In: Histocompatibility Testing. Terasaki PI, Ed. UCLA Press, Los Angeles, CA, 1980: 955-1210.

10. Baur MP, Neugebauer M, Depp H, et al. Population Analysis on the Bases of Deduced Haplotypes from Random Families. In: His- 
tocompatibility Testing. Albert ED, Ed. Springer-Verlag, Berlin, 1984: 333-341.

11. Ersoy F. Tissue groups in Turkish populations. J Turk Pediatrics 23: 79, 1980.

12. Altman R, Alarcon G, Appelrouth D, et al. The American college of rheumatology criteria for the classification and reporting of osteoarthritis of the hand. Arth Rheum 33: 1601-1610, 1990.

13. Kellgren JH, Lawrence JS. Radiological assessment of osteoarthrosis. Ann Rheum Dis 16: 494-502, 1957.

14. Altman RD. The classification of osteoarthritis. J Rheumatol Suppl 43: 42-43, 1995.

15. Kraus VB, Jordan JM, Doherty M, et al. The Genetics of Generalized Osteoarthritis (GOGO) study: study design and evaluation of osteoarthritis phenotypes. Osteoarthr Cartilage 15: 120-127, 2007.

16. Tokgoz G, Duzgun N, Turgay M, Kınıklı G, Duman M, Olmez U. The distribution of HLA-A, B and C antigens in Turkish population. Turk J Med Res 11: 32-36, 1993.

17. Basaran N. Tibbi Genetik. 6th ed. Eskisehir, Bilim Teknik Kitabevi, 1996.

18. Arnaiz-Villena A, Karin M, Bendikuze N, et al. HLA alleles and haplotypes in the Turkish population: relatedness to Kurds, Armenians and other Mediterraneans. Tissue Antigens 57: 308-317, 2001.

19. Ucar F, Ovalı E, Pakdemir A, et al. HLA Alleles and haplotypes in the East Black Sea Turkish population. Transpl P 36: 2610$2614,2004$.
20. Kalichman L, Hernández-Molina G. Hand osteoarthritis: An epidemiological perspective. Semin Arthritis Rheu 39: 465-476, 2010.

21. Das SK, Farooqi A. Osteoarthritis. Best Pract Res Clin Rheumatol 22: 657-675, 2008.

22. Saito I, Koshino T, Nakashima K, Uesugi M, Saito T. Increased cellular infiltrate in inflammatory synovia of osteoarthritic knees. Osteoarthr Cartilage 10: 156-162, 2002.

23. Wakitani S, Imoto K, Mazuka T, Kim S, Murata N, Yoneda M. Japanese generalised osteoarthritis was associated with HLA class I: a study of HLA-A, B, Cw, DQ, DR in 72 patients. Clin Rheumatol 20: 417-419, 2001.

24. Pattrick M, Manhire A, Ward AM, Doherty M. HLA-A, B antigens and $\alpha 1$-antitrypsin phenotypes in nodal generalised osteoarthritis and erosive osteoarthritis. Ann Rheum Dis 48: 470-475, 1989.

25. Clague RB, Morgan K, Collins I, Pattrick M, Doherty M. Absence of autoimmunity to type II collagen in generalised nodal osteoarthritis. Ann Rheum Dis 50: 769-771, 1991.

26. Merlotti D, Santacroce C, Gennari L, et al. HLA antigens and primary osteoarthritis of the hand. J Rheumatol 30: 1298-1304, 2003.

27. Kuby J. Major histocompatibility complex. Immunology. 3rd ed. Van Hoffman Press, New York, 1997.

28. Spector TD, Cicuttini F, Baker J, Loughlin J, Hart D. Genetic influences on osteoarthritis in women: a twin study. Brit Med J 312: 940-943, 1996

(C) 2011 The Japanese Society of Internal Medicine

http://www.naika.or.jp/imindex.html 